\title{
Contagious yawning and infant imitation
}

\author{
ROBERT R. PROVINE \\ University of Maryland Baltimore County, Catonsville, Maryland
}

\begin{abstract}
Several authors have suggested that the neonate's presumed ability to imitate the facial expressions or gestures of adult models may be the result of ethological fixed action patterns released by sign stimuli. Contagious yawning of adults is a precedent for such a facial fixed action pattern (i.e., a yawn) triggered by a facial stimulus (i.e., an observed yawn). Contagious yawning is an easily studied pseudoimitative act which can provide insights into both the problem of infant imitation and the more general issues concerning the detection and processing of information about faces. Contagious yawning also provides a reliable classroom demonstration of released behavior that always generates student interest and participation.
\end{abstract}

The ability of human newborns to imitate modeled facial expressions and gestures has attracted considerable and sometimes critical attention from a wide range of behavioral scientists (e.g., Field, Woodson, Greenberg, \& Cohen, 1982; Meltzoff \& Moore, 1977, 1983). Although there seems to be an increasing acknowledgement that some type of infant imitative capacity does exist, there is little agreement about the range of imitative acts (see, e.g., Field et al., 1983; Kaitz, Meschulach-Sarfaty, Auerbach, \& Eidelman, 1988) or the underlying perceptualcognitive mechanism (see, e.g., Jacobson \& Kagan, 1979; Kaitz et al., 1988; Masters, 1979; Meltzoff \& Moore, $1977,1979,1983)$. Tongue protrusion by an infant in response to a like gesture performed by an adult model is a frequently mentioned "imitative" act. Meltzoff and Moore $(1977,1983)$ suggest that this behavior is accomplished by the infant's relating proprioceptive motor information about its own unseen body movements to its representation of the visually perceived model. However, Kaitz et al. (1988) and others (Jacobson, 1979; Jacobson \& Kagan, 1979; Masters, 1979) caution that such behavior may not be true imitation, because this term implies the involvement of a complex intermodal matching process (as suggested by Meltzoff \& Moore, 1977). Instead, they suggest that the action of the model may trigger an involuntary movement of the infant that only mimicks imitation. For example, the apparent imitation may be an ethological "fixed action pattern" (tongue protrusion by the infant) that is "released" (evoked) by a "sign stimulus" (tongue protrusion by the model) (Kaitz et al., 1988). Although too little is known about the production of infant facial expressions and gestures to evaluate the releasing stimulus hypothesis, there is indeed a precedent for a facial, pseudoimitative, releasing process in adults.

Contagious yawning involves the release of a fixed action pattern (the yawn) by a sign stimulus (the observed yawn) (Provine, 1986). Yawning is a common behavior

Requests for reprints should be sent to Robert R. Provine, Department of Psychology, University of Maryland Baltimore County, Catonsville, MD 21228. easily studied in adults, who are more readily available, cooperative subjects than newborns. Adults can also introspect and verbally report their experiences. Although the study of contagious yawning cannot directly test hypotheses about behavior such as infant tongue protrusion, it can teach us about released behavior and its relevance to the problem of infant imitation. Contagious yawning also provides an interesting and always reliable classroom demonstration of released behavior that can be part of discussions of either infant imitation or human ethology.

Anyone who has yawned in response to observed yawns has experienced the triggering of a facial expression (the yawn) by a releasing stimulus (the observed yawn). Such yawn-evoked yawns are not the result of a conscious desire to imitate the yawner. An observed yawn initiates a series of apparently automatic neurobehavioral events that culminate in a yawn in the observer. The contagion of yawning has been confirmed experimentally with collegeaged subjects (Provine, 1986). Visually observed yawns are potent yawn-producing stimuli. Most subjects (55\%) viewing a 5-min long series of 30 yawns yawned within 5 min of viewing the first yawn. The latency of the evoked yawns was rather long and variable, ranging from seconds up to minutes; fixed action patterns are not released with the reliability and short and regular latencies usually associated with reflexes. Nonvisual stimuli are also effective in evoking yawns. Even reading about or thinking about yawning produces either yawns or the temptation to yawn in most subjects. The wide variety and potency of yawn-producing stimuli contributes to the contagion of yawning.

Because yawning is easy to produce (many readers may already be yawning), it provides a convenient demonstration of the fixedness of a fixed action pattern. Typical yawns last about $6 \mathrm{sec}$ (durations range from about 3 to $10 \mathrm{sec}$ or more), and individual differences in yawn duration are maintained for at least several weeks (Provine, 1986). This stability in duration is consistent with the property of typical intensity, a characteristic of ethological fixed action patterns. Fractional yawns are rarely 
produced. Once a yawn is initiated, it goes to completion. Everyone is familiar with the difficulty of stifling a yawn. The route of inhalation during the first phase of a yawn is also highly stereotyped. In contrast to normal breathing, which can be done through either the nose or the mouth, it is difficult, if not impossible, for most people to seal their lips and perform satisfactory yawns by inhaling through their noses (Provine, Tate, \& Geldmacher, 1987). The characteristic gaping of the jaw is another fixed component of the yawn. Most people are not able to produce a satisfying yawn with clenched teeth, although inhalation and exhalation can be performed through the teeth (Provine, 1986).

This commentary has focused on contagious yawning as a precedent for facial imitation and as an example of a released fixed action pattern, but the development of contagious yawning is itself worthy of study. Although yawning is performed throughout the lifespan (Gesell, 1928) and may be present as early as 11 weeks after conception (DeVries, Visser, \& Prechtl, 1982), the development of contagious yawning has not been studied systematically. One of the rare references to the topic is the observation of 3 children that led Piaget (1951) to conclude that yawning becomes contagious only during the 2nd year. If subsequent research confirms this chronology, the releasing mechanism that triggers contagious yawns develops and becomes active long after the motor pattern generator for yawning. The very early development of yawning in the human embryo suggests that the motor act has a much more ancient phylogenetic origin than the releasing mechanism, which develops postnatally. This phylogenetic sequence accords with the performance of the yawning act but not with contagious yawning by most vertebrates (Provine, 1986). The yawning act probably evolved in early vertebrates as a homeostatic response to one or several yet to be defined physiological states. Contagious yawning apparently evolved recently, as a mechanism for coordinating the behavioral and perhaps the physiological state of a group (Provine \& Hamernik, 1986; Provine, Hamernik, \& Curchack, 1987).

Because yawns are triggered by visually observed yawns, yawning can be used to behaviorally assay the yawn-evoking potency of various facial features (Provine, 1988). Thus used, studies of yawning and perhaps infant tongue protrusion and other presumed examples of facial imitation join those of prosopagnosia (face nonrecognition) in brain-damaged humans (Meadows, 1974; Whiteley \& Warrington, 1977) and of face-specific neurons in monkeys (Bruce, Desimone, \& Gross, 1981; Parrett, Mistlin, \& Chitty, 1987; Parrett, Rolls, \& Caan, 1982) and sheep (Kendrik \& Baldwin, 1987), which suggest that special neural mechanisms may be involved in the detection and processing of information about faces. Research on contagious yawning, tongue protrusion, and other potential examples of released behavior (e.g., Eibl-
Eibesfeldt, 1975) should be assigned a high priority by students of human behavior development. Such analyses contribute to our understanding of processes central to both human development and cognitive neuroscience.

\section{REFERENCES}

Bruce, C., Desimone, R., \& Gross, C. G. (1981). Visual properties of neurons in a polysensory area in superior temporal sulcus of the macaque. Journal of Neurophysiology, 46, 369-384.

DeVries, J. I., Visser, G. H. A., \& Prechtl, H. F. R. (1982). The emergence of fetal behavior: I. Qualitative aspects. Early Human Development, 7, 301-322.

EIBL-EIBESFELDT, I. (1975). Ethology, the biology of behavior (2nd ed.). New York: Holt, Rinehart \& Winston.

Field, T. M., Woodson, R., GreenberG, R., \& CoHen, D. (1982). Discrimination and imitation of facial expressions by neonates. Science, 218, 179-181.

GESELL, A. (1928). The mental growth of the pre-school child. New York: Macmillan.

JACOBSON, S. W. (1979). Matching behavior in the young infant. Child Development, 50, 425-430.

JACOBSON, S. W., \& KaGaN, J. (1979). Note commenting on Meltzoff and Moore (1977). Science, 205, 215-217.

Kaitz, M., Meschulach-Sarfaty, O., Auerbach, J., \& EidelMAN, A. (1988). A reexamination of newborn's ability to imitate facial expressions. Developmental Psychology, 24, 3-7.

KENDRICK, K. M., \& BALDWIN, B. A. (1987). Cells in temporal cortex of conscious sheep can respond preferentially to the sight of faces. Science, 236, 448-450.

MASTERS, J. C. (1979). Note commenting on Meltzoff and Moore (1977). Science, 205, 215.

Meadows, J. C. (1974). The anatomical basis of prosopagnosia. Journal of Neurological \& Neurosurgical Psychiatry, 37, 489-501.

Meltzoff, A. N., \& Moore, M. K. (1977). Imitation of facial and manual gestures by human neonates. Science, 198, 75-78.

Meltzoff, A. N., \& Moore, M. K. (1979). Note responding to Anisfeld, Masters, and Jacobson and Kagan's comments on Meltzoff and Moore (1977). Science, 205, 217-219.

Meltzoff, A. N., \& MoOre, M. K. (1983). Newborn infants imitate adult facial gestures. Child Development, 54, 702-709.

Perrett, D. I., Mistlin, A. J., \& Chitty, A. J. (1987). Visual neurons responsive to faces. Trends in Neuroscience, 10, 358-364.

Perrett, D. I., Rolls, E. T., \& CAAN, W. (1982). Visual neurons responsive to faces in the monkey temporal cortex. Experimental Brain Research, 47, 329-342.

Piaget, J. (1951). Play, dreams and imitation in childhood. New York: Norton.

Provine, R. R. (1986). Yawning as a stereotyped action pattern and releasing stimulus. Ethology, 72, 109-122.

Provine, R. R. (1988). Faces as releasers of contagious yawning: An approach to the neural basis of face perception. Society for Neuroscience Abstracts, 14(Pt. 1), 218.

Provine, R. R., \& Hamernik, H. B. (1986). Yawning: Effects of stimulus interest. Bulletin of the Psychonomic Society, 24, 437-438.

Provine, R. R., Hamernik, H. B., \& Curchack, B. C. (1987). Yawning: Relation to sleeping and stretching in humans. Ethology, 76, 152-160.

Provine, R. R., Tate, B. C., \& Geldmacher, L. L. (1987). Yawning: No effect of $3-5 \% \mathrm{CO}_{2}, 100 \% \mathrm{O}_{2}$, and exercise. Behavioral \& Neural Biology, 48, 382-393.

Whiteley, A. M., \& Warrington, E. K. (1977). Prosopagnosia: A clinical, psychological, and anatomical study in three patients. Journal of Neurological \& Neurosurgical Psychiatry, 67, 394-430.

(Manuscript received July 29, 1988.) 